\title{
Discussion on Implementation Countermeasures of Green Freight on Hunan Rural Highway Based on Internet of Things*
}

\author{
Shijun Yuan \\ Hunan Modern Logistics College \\ Changsha, China
}

\author{
Jianhua Chen** \\ Hunan Modern Logistics College \\ Changsha, China \\ **Corresponding Author
}

\begin{abstract}
The rapid development of Internet of things technology has laid a foundation for the implementation of green freight on rural highways in Hunan. This paper analyzes the existing problems of rural highway freight in Hunan, and presents some countermeasures in terms of policies, standards, implementation subjects and investment and financing system.
\end{abstract}

Keywords-the Internet of things; green freight; countermeasures

\section{INTRODUCTION}

The development of rural economy in Hunan Province is a significant constituent part in the development of whole social economy of Hunan Province. During its economic development, Hunan Province promotes a development mode including new industrialization, new urbanization and rural integration, and builds a new Hunan country with the theme of "green, ecology and environmental protection". As an inseparable part of rural social and economic development in Hunan, logistics activities may also pollute the environment. For instance, one of main causes of the current urban environmental pollution is fuel pollution from transportation vehicles, so green freight is an inevitable choice for the development of rural freight industry in Hunan Province. Meanwhile, the Internet of things industry has developed rapidly in recent years, which has laid a solid technical foundation for the construction of smart cities and the implementation of smart logistics. Therefore, how to exploit the advantages of Internet of things technology to the full in rural Hunan and how to build a green freight system in rural Hunan will become a topic worth discussing in the construction of rural Hunan.

\section{MAIN PROBlEMS IN THE DEVELOPMENT OF RURAL HIGHWAY FREIGHT INDUSTRY IN HUNAN}

In 2018, the total amount of social logistics in the

*Fund: 2018 Hunan philosophy and social science fund base project "Research on the Establishment of Rural Logistics System in Hunan Province Based on the Strategy of Rural Revitalization" (18JD43) and the phased research result of Hunan Social Science Achievement Review Committee "Research on the Countermeasure System of Rural Logistics Development Based on the Strategy of Rural Revitalization" (XSP19YBC277). province was 10.85762 trillion yuan, with a year-on-year increase of $8 \%$ based on comparable price. In terms of composition, agricultural products logistics totaled 648.89 billion yuan, with an increase of $3.5 \%$; industrial goods logistics totaled 5.52661 trillion yuan, with an increase of $7.3 \%$; import goods logistics totaled 105.28 billion yuan, with an increase of $17.6 \%$; the logistics of goods from other provinces totaled 3.5112 trillion yuan, with an increase of $8.6 \%$; renewable resources logistics totaled 16.57 billion yuan, with an increase of $3.6 \%$; the logistics of unit and resident goods totaled 1.04907 trillion yuan, with an increase of $23.4 \%$.

After decades of development, the rural logistics industry in Hunan Province has begun to take shape. Generally speaking, the logistics industry is still in the initial stage of transformation from traditional logistics to modern logistics, but there is still a big gap between rural logistics and urban logistics in terms of its development trend and demand of economic development.

\section{A. Backward Means of Transport}

Rural freight in Hunan Province is mainly carried out by highway. The survey finds that there are generally excessive exhaust emission from vehicles, excessive use of vehicles, and poor vehicle conditions in highway freight enterprises. The phenomenon of "waste of resources and environmental pollution" is prominent in freight transport. However, new environment-friendly and energy-saving urban freight and distribution vehicles are rarely used.

\section{B. Less Application of Internet of Things and Other New Technologies}

In recent years, the high and new technology represented by the Internet of things technology is booming. The application of new technology in the field of freight can optimize the distribution route, improve the transportation efficiency, track the status of freight vehicles in real time, and reduce the transportation energy consumption in the process of freight. At present, only a small number of rural freight enterprises in Hunan have changed their ideas earlier, and adopted new software or technologies including GPS, GIS, RFID, etc. The wide application of these new 
collection of a large number of freight information and realize the transmission of information by means of efficient communication technology. In addition, the Internet of things not only collects information, but more importantly, it makes comprehensive analysis and processing based on the collected information. According to big data analysis, it can intelligently control all links of freight transportation and related facilities and equipment to maximize the utilization efficiency of resources and logistics service efficiency in the field of freight transportation.

\section{A. Intelligent Management of Freight Infrastructure}

Freight infrastructure is the cornerstone of the development of freight industry. A sound and wellfunctioning freight infrastructure is the guarantee of safe and efficient operations in the freight industry. Freight infrastructure can sense the status of freight infrastructure in real time by means of sensor technology of the Internet of things so that freight infrastructure can be maintained in an emergency.

\section{B. Monitoring of the Running State of Freight Vehicles}

On the premise that management of freight infrastructure has been perfected, the Internet of things technology can be used to further monitor the running state of freight vehicles in real time, including their serviceable condition, running speed, cargo quantity, route information, etc. The automatic detection of running state of freight vehicles can be completed by using infrared technology, piezoelectric leaflet, ground induction coil and other sensor technology and communication technology in the Internet of things.

\section{TECHNOLOGY ON THE DEVELOPMENT OF RURAL HighWAY FREIGHT IN HUNAN PROVINCE}

III. MAIN INFLUENCES OF INTERNET OF THINGS

The Internet of things is defined as the "Internet in which everything is connected". It is an extension and expansion of Internet-based networks. It combines all kinds of information sensing devices with the Internet to form a huge network, realizing the interconnection of people, machines and things at any time and at any place

Internet of things is an important part of the new generation of information technology. It is also called universal interconnection in IT industry, which means that all things in this circle are connected. Therefore, the Internet of things is the "Internet in which everything is connected". It has two meanings: first, the core and foundation of the Internet of things is still the Internet, which is an extension and expansion of the Internet. Second, its user sides extend to any goods to exchange information and communicate with each other. Therefore, the Internet of things, by definition, is a kind of network that connects any object with the Internet for information exchange and communication through information sensing devices including radio frequency identification, infrared sensor, global positioning system and laser scanner based on the agreed protocol, so as to realize the intelligent identification, positioning, tracking, monitoring and management of the object.

A large number of sensors and other devices are provided for infrastructure, means of transportation and related equipment of freight transportation, so as to facilitate the

\section{Comprehensive Coordination of All Elements of Freight System}

GPS, GIS, RFID, IC card, video monitoring and wireless communication technology can be adopted to analyze the running state of freight infrastructure and freight vehicles in a comprehensive way, and dynamically sense the loading status of each freight infrastructure and running location and speed of freight vehicles. Furthermore, it is necessary to combine the corresponding route planning and scheduling software to complete intelligent scheduling and improve freight efficiency and security.

\section{IMPLEMENTATION COUNTERMEASURES OF GREEN FREIGHT ON HUNAN RURAL HIGHWAY BASED ON INTERNET OF THINGS \\ A. Formulation of Relevant Laws and Regulations and Encouragement Policies for the Coordinated \\ Development of Various Regions in Hunan Province}

Rural Hunan is further accelerating the pace of coordinated development of various regions, which not only means a city mergence in hardware, but also the coordination and unity from the perspective of software. However, it is impossible to push green freight in rural Hunan only with the help of a single freight transport enterprise. It mainly depends on the logistics directors and related government 
for the construction of traffic information mainly come from highway and port charging, which cannot meet the current construction demands. Therefore, it is necessary to set up special funds for green freight Internet of things technology, and industrialization and demonstration projects, establish an Internet of things investment and financing system for "green freight", and support the research and development of key technologies for "green freight" of the Internet of things, as well as the construction of public service platforms, key projects and infrastructure for freight.

\section{CONCLUSION}

In spite of some application of the Internet of things in the freight industry, a range of issues such as technology, culture and policies also need to be addressed. However, it is foreseeable that in the near future, Internet of things technology will certainly revolutionize the "green freight" industry in rural Hunan.

\section{REFERENCES}

[1] Zhao Guoqing. The Application of Internet of Things in Logistics Transportation [J]. China Commerce. 2010 (6). p165. (in Chinese)

[2] Liu Zhenshan. On the Application of Internet of Things Technology in Transportation Industry $[\mathrm{J}]$. Transportation Information Industry. 2012. 12. P136. (in Chinese)

[3] Fu li, et al. Design for Transportation IOT Framework [J]. Transportation Standardization. 2014 (10). p115-118. (in Chinese)

[4] Yao Yuzhang, et al. Some Thoughts on Promoting the Orderly and Healthy Development of Internet of Things in Transportation Industry [J]. Waterway Transportation Digest. 2013 (08). p78-79. (in Chinese)

[5] Chen Jianbiao. Study on the Necessity and Countermeasures of Strengthening the Development of Green Transportation in China [J]. Securities \& Futures of China. 2013 (07). P136. (in Chinese) guidelines for the green freight Internet of things, and establish a standard system for the green freight Internet of things, so as to realize the linkage development of the Internet of things industry and the freight industry.

\section{Carrying Out Demonstration and Guidance for Enterprises and Cultivating the Green Freight Service Principal}

Most of freight enterprises do not know enough about the environmental pollution from freight transport, lack sense of responsibility for environmental protection, and have not formed the management concept of green logistics. Therefore, in the early stage, the government can establish the "green freight" development fund, and support a group of demonstration projects and demonstration enterprises that advance the green logistics through the application of Internet technology. At the same time, it also can set up a benchmark for green freight, accumulate relevant successful experience, and lay the foundation for the large-scale promotion of the application of Internet of things in the freight industry.

\section{Establishing the Investment and Financing System for "Green Freight"}

The construction of the "green freight" system based on the Internet of things is costly. However, the previous funds 